\title{
THE INFLUENCE OF USING SQP2RS (SURVEY, QUESTION, PREDICT, READ, RESPOND, SUMMARIZE) STRATEGY TO IMPROVE STUDENTS' READING COMPREHENSION
}

\author{
Jusak Patty \\ jusak.patty@gmail.com \\ Lecturer of English Language Education Study Program \\ FKIP Unpatti Ambon
}

\begin{abstract}
Reading is the foundation that supports the success of academic achievement and hence it should be given top priority. The objective of this study was to find out the influence of using SQP2RS strategy towards students' reading comprehension. This study was a pre experiment research using one-group pretest - posttest design. The sample of this study consisted of 38 students of XI Science grade of SMA N 2 Ambon, which was selected purposely. The data was collected by using an essay test and analysed statically. The results showed there was a positive and significant influence of using SQP2RS strategy toward students reading comprehension.
\end{abstract}

Key Words: The Influence, SQP2RS (Survey, Question, Predict, Read, Respond, Summarize), Strategy, Students,'

Reading Comprehension

\section{Introduction}

In learning English, someone should master four basic skills such as listening, speaking, reading and writing. Reading as one of receptive skills has been giving great contributions and plays important roles in human life. McDonough and Shaw (as cited in Pan, 2009) stated, "As a skill, reading is clearly one of the most important". This means mastery is essential since it can enhance a person' knowledge and quality of thinking.

Reading is actually a complex activity that involves both perception and thought, even though many people consider it as a simple and static process (Bernhard et al, 2003; p.6). When people read, there goes an interaction occurring between readers and writers through text resulting in inputs through an active process.

In relation with conducting this research, the researcher had conducted a preliminary study at SMA N 2 Ambon, at eleventh science grade. The results showed that the main problem in reading was students' lack of comprehension in reading due to several factors. First, there were no pre-reading activities during the learning process to support the activation of schemata. Colorado (2008) stated "pre-reading activities can engage students' interest, activate prior knowledge, or pre-teach potentially difficult concepts and vocabulary". The teacher, however, failed to implement it.

Another factor was students were not motivated to be an autonomous learner. This occurred due to the teacher not giving the chance for the students to 
clarify what they had read. When students gave wrong answers, the teacher directly gave correct answers. Meier (2010) stated "clarifying encourages students to think about their own thought process during reading. It helps students to learn, be actively involved and monitor their comprehension as they read". The process of clarifying only went in one direction.

Based on the explanation above, the researcher was interested to implement a strategy to find out its influence toward students' reading comprehension. The strategy is SQP2RS, which stands for Survey, Question, Predict, Read, Respond and Summarises. It is a multi-step strategy developed by Marry Ellen Vogt to help students engage in each phase of the reading process, building motivation and enhancing comprehension.

This study was an attempt to answer the research question "does the use of SQP2RS strategy influence students comprehension in answering all levels of comprehension questions?"

\section{Review of Literature}

\section{The Concept of Reading Comprehension}

Reading is a process of gaining the meaning of the language, sharing the information, and comprehending the content of the texts properly. It is an individual activity and has to be done on his own for better understanding. Nunan (2003; p.68) stated, "Reading is a fluent process of readers combining information from a text and their background to build meaning". Basically the reason for reading is comprehension which is an action of grasping meaning with the intellect. Bazan and Kudo (2009;p.6) mentioned that there are three different types of comprehension. First, literal comprehension centers on the recognition or evocation of primary details, main ideas, sequences, or cause-effect, from information that is explicit in the text.

Second, inferential comprehension requires making logical connections among facts in texts, deducing events, making generalizations, interpreting facts, and relating the content to previous knowledge or personal experiences, from information implicit in the text (Camba, 2006). Lastly, critical comprehension demands the readers to make evaluation and an analysis about what is being read.

Reading comprehension is the act of understanding what readers are reading from connected text. It involves word knowledge (vocabulary) as well as thinking and questioning. Therefore reading comprehension is not a passive process but an active one (Bernhardt et.al 2003; p.14). The reader actively engages with the text to construct meaning. This active engagement includes making use of prior knowledge. It involves drawing inferences from the words and expressions that a writer uses to communicate information, ideas and viewpoints.

\section{Common Problems in Reading Comprehension}

It is undeniable that reading comprehension has become an issue that has being discussed for years. For many students, comprehending a text becomes a matter. The explanation below will describe some causes that make readers have poor reading comprehension. 
First, language becomes a matter for someone. To read and to understand a book, someone has to know a particular language and if it is not so, he will be unable to comprehend what is being read. The role of language can be associated with the function of the hand of a pianist. A pianist is not a pianist if he could not play a piano by his hand. Therefore, if a child's knowledge of English is poor, then his reading will also be poor, and naturally his reading comprehension.

Second, the foundational skills of reading have not been automatized. The poor reader is forced to apply all his concentration to word recognition, and therefore has "no concentration left" to decode the written word, and as a result he will not be able to read with comprehension.

Last, the reader is unable to decode the written word: The decoding of the written word is a very important aspect of the reading act. Without being able to decode the written word, reading comprehension is impossible.

\section{The Ways to Improve Reading Comprehension}

The ability to understand and to remember reading material becomes a major factor to support students achieving their successfulness in school and everyday life. According to Logsdon, there are several tips that can be used to improve ability and success in reading and learning.

1. Doing Pre Reading Tasks. Doing a pre-reading task helps students to understand the text that will be read by asking as much information as they have already known and recalling as information as they can relate in the text.

2. Researching the Topic. Researching topics makes students easier to comprehend the text. These following question can be used to research the topic:

a. What kind of text is this?

b. What new information did I learn and what do I expect to learn?

c. Is this text informative or entertaining, fact or fiction?

d. What interests me about this book?

3. Learning New Words. Reading will be done easily when someone has many vocabularies. It provides an opportunity to comprehend more about what is being read. Listing unfamiliar vocabulary words, searching the meanings of the word in the dictionary and writing definitions down will help students to more comprehend their reading if they have insufficient vocabulary.

4. Reflecting on the Material and Asking Questions. What comes in students' mind as they read the text would encourage the students to explore more about the text they are going to read. The students will try to answer their question and try to make reflection based on their background knowledge or searching for other extra reading materials.

\section{SQP2RS as One of the Strategies to Improve Students' Reading Comprehension}

SQP2RS strategy is one of metacognition strategies that enables readers to do the process of thinking about thinking. Taylor (1999; p.1) defines metacognition as "an appreciation of what one already knows, together with a 
correct apprehension of the learning task and what knowledge and skills it requires, combined with the agility to make correct inferences about how to apply one's strategic knowledge to a particular situation, and to do so efficiently and reliably". The more students are aware of the thinking process as they learn, the more they can control such matters as goals, dispositions and attention.

As a part of metacognition, SQP2RS allows the readers to purposely monitor their thinking. This strategy is characterized by matching thinking and problem-solving strategy to particular learning situations, clarifying purposes for learning, monitoring one's own comprehension through self-questioning and taking corrective action if understanding fails. It is designed for expository text based on the Sheltered Instruction Observation Protocol- SIOP Model and used to facilitate instruction in the content teaching area. The implementation of this strategy is as follow:

\section{- Survey}

This step involves the process of previewing, skimming and scanning which aims to let the students to see the big pictures of the text. They will try to explore the text without reading any paragraph and determine the key concepts that will be learnt.

\section{- Question}

Students will come up with at least three different questions of their own which likely be answered as they read the text.

\section{- Predict}

Students will come up with three or four key concepts, based on previously generated questions; they think they will answer while reading.

\section{- Read}

While reading, students are required to find the answers of their questions and confirm or disprove their predictions.

\section{- Respond}

Students answer the questions and formulate new ones for the next section of the text. The teacher leads discussion of key concepts and clarifies any misunderstanding.

\section{- Summarize}

Students summarize the key concepts using appropriate key vocabularies.

\section{Methodology}

This study was a pre experimental research using one-group pretestposttest design. This design followed the model of Jemmett and Jemmett (1992):

\section{$\mathrm{O}_{1}-\mathrm{X}-\mathrm{O}_{2}$}

$\mathrm{O}_{1} \quad$ : Pre-test

$\mathrm{X}$ : Treatment

$\mathrm{O}_{2} \quad$ : Post-test

This study was conducted at SMA N 2 Ambon with a total sample of 38 students. The sample was selected purposely. The instrument of data collection data was an essay test and the result of the test would be analysed using the formula of Pantouw (1999). 
Grade Mastery $=\frac{\text { total score of correct asnwers }}{\text { total score of all questions }} \times 100 \%$

To find mean score, deviation standard, error standard, and t-test, the researcher used formula of Sudijono (2010):

- Mean

$$
M=\frac{\sum f x}{N}
$$

In which:

$\mathrm{M} \quad=$ Mean

$\sum f x=$ Total amount of the score

$\mathrm{N} \quad=$ Total number of students

- Deviation Standard

$S D=\sqrt{\frac{\sum f x^{2}}{N}-\left(\frac{\sum f x}{N}\right)^{2}}$

In which:

SD $=$ Deviation standard

$\sum f x^{2}=$ Total amount of the score

$\sum f x=$ Quadrate of total amount of the score

$\mathrm{N} \quad=$ Total number of students

- Error Standard

$S E_{M}=\frac{S D}{\sqrt{N-1}}$

In which:

$S E_{M} \quad=$ Error standard

$S D \quad=$ Deviation standard

$N=$ Total number of students

\section{Result}

\section{Students' Result in Pre-Test}

Before the implementation of SQP2RS strategy, the researcher had conducted pre-test in order to find out students' initial ability in reading comprehension. The result of pre-test showed that most students were in the category of inadequate with grades ranges from 55- 69.

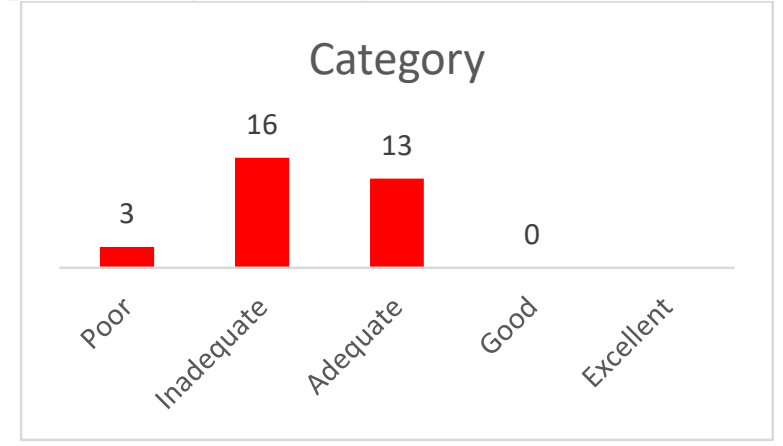

Figure 1. Pre-test Result 
The result of the pre-test was used to calculate mean, deviation standard and error standard.

\begin{tabular}{|c|c|c|c|}
\hline $\begin{array}{c}\text { Score } \\
(\mathbf{Y})\end{array}$ & $\begin{array}{c}\text { Number } \\
\text { of } \\
\text { Students } \\
\text { (f) }\end{array}$ & fY & $\mathbf{F Y}^{\mathbf{2}}$ \\
\hline 26 & 2 & 52 & 1352 \\
\hline 31 & 1 & 31 & 961 \\
\hline 40 & 5 & 200 & 8000 \\
\hline 43 & 1 & 43 & 1849 \\
\hline 45 & 8 & 360 & 16200 \\
\hline 50 & 2 & 100 & 5000 \\
\hline 57 & 2 & 114 & 6498 \\
\hline 59 & 3 & 177 & 10443 \\
\hline 62 & 1 & 62 & 3844 \\
\hline 64 & 3 & 192 & 12288 \\
\hline 67 & 1 & 67 & 4489 \\
\hline 69 & 3 & 207 & 14283 \\
\hline 76 & 2 & 152 & 11552 \\
\hline 79 & 1 & 79 & 6241 \\
\hline 81 & 3 & 243 & 19683 \\
\hline & $\mathrm{N}=38$ & $\sum f Y=$ & $\sum f Y^{2}=122683$ \\
& & 2079 & \\
\hline
\end{tabular}

Table.1. Students' Score

- Mean

$$
M=\frac{\sum f y}{N}=\frac{2079}{38}=54,71
$$

- Deviation Standard

$$
\begin{aligned}
S D & =\sqrt{\frac{\sum f y^{2}}{N}-\left(\frac{\sum f y}{N}\right)^{2}} \\
& =\sqrt{\frac{122683}{38}-\left(\frac{2079}{38}\right)^{2}} \\
& =\sqrt{3228.50-54.71^{2}} \\
& =\sqrt{3228.50-2993.24} \\
& =\sqrt{253.26} \\
& =15.34
\end{aligned}
$$

- Error Standard 


$$
S E_{M}=\frac{15.34}{\sqrt{37}}=\frac{15.34}{6.08}=2.52
$$

\begin{tabular}{|c|c|c|c|c|}
\hline Test & $\begin{array}{c}\text { Number of } \\
\text { Students }\end{array}$ & Mean Score & $\begin{array}{c}\text { Deviation } \\
\text { Standard }\end{array}$ & $\begin{array}{c}\text { Error } \\
\text { Standard }\end{array}$ \\
\hline Pre-Test & 38 & 54.71 & 15.34 & 2.52 \\
\hline
\end{tabular}

Table 2. Students' Mean Score and Deviation Standard in Pre-Test

The data above indicates that students' performance in pre-test was low. Based on the data distribution and score description of pre-test, most of the students could not answer the questions due to lack of reading comprehension. They did not understand the questions and tended to make mistakes.

\section{Students' Result in Post-Test}

After the implementation of SQP2RS strategy, the researcher had conducted pre-test in order to find out the influence of this strategy towards reading comprehension. The result of pre-test showed that most students had significant improvement categorized into excellent with grades ranges from 85100.

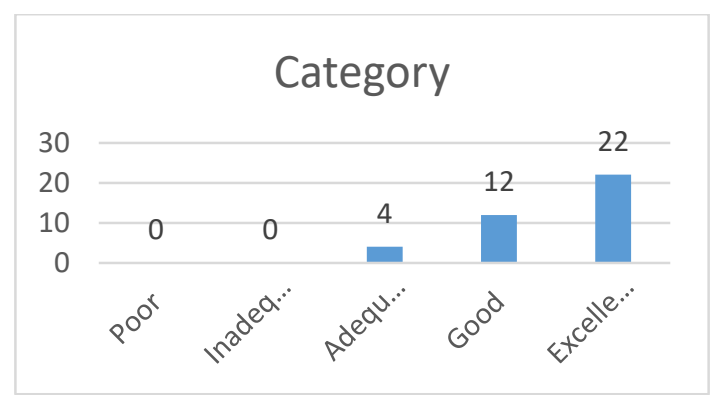

Figure 2. Post-test Result

The result of pre -test was used to calculate mean, deviation standard and error standard.

\begin{tabular}{|c|c|c|c|}
\hline $\begin{array}{c}\text { Score } \\
(\mathbf{X})\end{array}$ & $\begin{array}{c}\text { Number } \\
\text { of } \\
\text { Students } \\
\text { (f) }\end{array}$ & $\mathbf{f X}$ & $\mathbf{F X}^{\mathbf{2}}$ \\
\hline 69 & 4 & 276 & 19044 \\
\hline 71 & 1 & 71 & 5041 \\
\hline 76 & 4 & 304 & 23104 \\
\hline 81 & 7 & 567 & 45927 \\
\hline 86 & 5 & 430 & 36980 \\
\hline 88 & 3 & 264 & 23232 \\
\hline 93 & 7 & 651 & 60543 \\
\hline 100 & 7 & 700 & 70000 \\
\hline & $\mathrm{N}=38$ & $\sum f Y=$ & $\sum f Y^{2}=283871$ \\
\hline
\end{tabular}




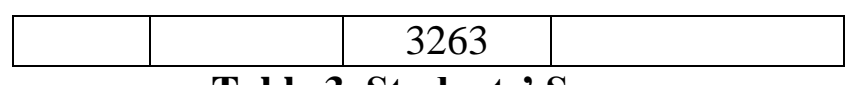

Table.3. Students' Score

- Mean

$$
M=\frac{\sum f y}{N}=\frac{3263}{38}=85,87
$$

- Deviation Standard

$$
\begin{aligned}
S D & =\sqrt{\frac{\sum f y^{2}}{N}-\left(\frac{\sum f y}{N}\right)^{2}} \\
& =\sqrt{\frac{283871}{38}-\left(\frac{3263}{38}\right)^{2}} \\
& =\sqrt{7470.29-85.87^{2}} \\
& =\sqrt{7470.29-7373.39} \\
& =\sqrt{96.90} \\
& =9.84
\end{aligned}
$$

- Error Standard

$$
S E_{M}=\frac{9.84}{\sqrt{37}}=\frac{9.84}{6.08}=1.62
$$

\begin{tabular}{|c|c|c|c|c|}
\hline Test & $\begin{array}{c}\text { Number of } \\
\text { Students }\end{array}$ & Mean Score & $\begin{array}{c}\text { Deviation } \\
\text { Standard }\end{array}$ & $\begin{array}{c}\text { Error } \\
\text { Standard }\end{array}$ \\
\hline Pre-Test & 38 & 85.87 & 9.84 & 1.62 \\
\hline
\end{tabular}

Table 4. Students' Mean Score and Deviation Standard in Pre-Test

The data above indicates that students' performance in post-test was significantly improved. Based on data distribution and score description, it can be concluded that most of the students had understood the text and were able to answer the questions. They could present all information clearly and concisely based on reading passages and give brief responses.

\section{Discussion}

Since the purpose of reading is to understand what is being read, comprehension is important to achieve that purpose. According to Benhard et. al. (2003:14) reading is an active process in which the reader actively engages with the text to construct meaning. This active engagement includes making use of prior knowledge. When the readers read, they combine the information from the text with their background knowledge to get meaning (Nunan, 2003:68).

To achieve better comprehension in reading, the readers can use SQP2RS strategy. As a part of metacognitive, this strategy allows the readers to solve textlevel problems by monitoring, evaluating, and revising their evolving interpretation of the text while reading. They then compare the emerging meaning 
to their background knowledge and make adjustments to incorporate new information to existing memory stores.

In its implementation, SQP2RS strategy is proven effective. It gives positive and significant influence that can be seen in students' improvement in answering comprehension questions from pre-test until post-test. If it is compared to the result of pre-test, most students $(42,1 \%)$ were categorized into "Inadequate" level in which their grades ranged from 40-54.99. Generally, students who belong to this level had significant problems with clarity, concision and organization. They also tended to make presented information difficult to understand. However, after the implementation of this strategy, these problems finally can be minimized. The data in post-test results has shown significant improvement of the students reading comprehension in which most of them (57,9\%) were categorized into "Excellent" with grades ranging from 85-100. These improvements include students' abilities to present all information clearly and concisely based on reading passage, give brief responses, provide the evidence that support their answers, make inferences and determine the purpose and type of text.

In further explanation below, the researcher will discuss some important elements that support the successfulness of this strategy.

\section{The Importance of Retrieving Students' Prior Knowledge in Reading Process.}

During the implementation of SQP2RS, the researcher could see that this strategy gave positive influence and significantly improved students ability in reading comprehension such as ability to activate prior knowledge. Cunningham (2007) stated that the most important factor in determining how much readers will comprehend and how well writers will be able to communicate about a given topic is their level of knowledge about that topic. It is obvious that activating prior knowledge during the teaching and learning process becomes one of the most important aspects that help readers to understand and to get the meaning of the text. Since the result of the preliminary study showed that one of the problems in reading comprehension dealing with pre-activities, SQP2RS strategy could overcome that problem. In this strategy, students were provided with pre-reading activities that help them to activate their prior knowledge. They were trained to survey, question, and predict the text before reading. These activities enabled them to be more aware with the text.

Fisher and Frey (2009) noted that a student's prior knowledge about a subject is probably the best predictor of reading comprehension. Furthermore, Gregory et.al (1991, as cited in Fisher and Frey, 2009) stated that the most wellknown effect of background knowledge is its ability to directly influence the understanding of what is read. Based on the statement above, it makes perfect sense that the more students know about a topic, the more likely it will be that they can comprehend what is written about it.

In this study, activating prior knowledge is one of the most important aspects that should be done in order to achieve the purpose of reading which is comprehension. Based on the researcher's experiences, after activating students' prior knowledge, students become more active and more interested to be involved 
in the classroom. This was shown during the teaching learning process in which most of them were able to make their own predictions before reading. In addition, they had better understanding towards the text and were able to answer the questions in whilst-reading activity.

\section{The Need of Monitoring and Clarifying in the Teaching Learning Process}

SQP2RS strategy allows the students to purposely monitor and clarify their reading and this was shown after students read the text. As students started to read, they constantly monitored themselves in order to make sure they understood what they were reading, for example, during the implementation of this strategy, the students' always noted the characteristics of the text. They also tried to find the answers of their own questions and justify their own predictions that had been previously made. In this stage, when students did not find the answers of their questions and predictions, the researcher helped them by asking students to reread and make new predictions based on the text. The students should do this corrective action in order to understand the text. According to Zimmerman and Hutchins (2003), monitoring lets the readers be aware when they are reading, whether a text is making sense or not. Monitoring allows the readers to quickly address problem areas with clarifying strategies in which the readers are taught to do what proficient readers do: they stop reading when a text no longer makes sense and implement various repair strategies. It engages students to identify unclear concepts, structures and passages and helps them to be actively involved with their reading.

\section{Conclusion}

The results of this study conclude that:

1. The implementation of SQP2RS gave positive and significant influence toward students' reading comprehension.

2. The students showed positive responses during the implementation.

3. SQP2RS strategy enables students to activate prior knowledge and monitor their learning process.

\section{References}

Bazan, J \& Kudo, I. (2009). Measuring beginner reading skills: an empirical evaluation of alternative instruments and their potential use for policymaking and accountability in Peru (Policy Research Working Paper 4812). Caribbean : Human Development Department

Bernhardt, E. B, Kamil, M.L, Muaka, A \& Pang, E. S. (2003). Teaching readingeducational practice series 12. Belgium: International Academy of Education

Cunningham, N. J. (2007). Level of Bonding to School and Perception of the School Environment by Bullies, Victims, and Bully Victims. The Journal of Early Adolescence, 27(4), 457-478. https://doi.org/10.1177/0272431607302940

Colorado, C. (2008). Pre-Reading Activities for ELLs. 
Fisher, D and N, Frey. (2009). Background Knowledge: The Missing Piece of the Comprehension Puzzle. Portsmouth, NH: Heinemann

Nunan, D. (2003). Practical English Language Teaching. USA: The McGrawHill Companies

Pan, Lichun. (2009). Sub-skills approach and extensive approach to reading in TEFL. Journal of Cambridge Studies 4(3), 112-120

Sudijono, A. (2010). Pengantar Statistik Pendidikan. Jakarta: Rajawali Press.

Taylor, S. (1999). Better learning through better thinking: Developing students' metacognitive abilities. Journal of College Reading and Learning, $30(1)$.

Zimmermann, S and Hutchins, C (2003). 7 keys to Comprehension. New York Three Rivers Press. 